\title{
Chancillería en colegio: la producción y circulación de papeles jesuitas en el siglo XVI ${ }^{1}$
}

\author{
Paul NeLLES \\ Carleton University, Ottawa \\ paul_nelles@carleton.ca
}

Fecha de recepción: 03/02/2014

Fecha de aceptación: 06/06/2014

\begin{abstract}
RESUMEN
La circulación de cartas, instrucciones y noticias jugó un papel esencial en la expansión de la Compañía de Jesús y en la coordinación a la larga distancia de los esfuerzos de los jesuitas. La comunicación dentro de la orden ignaciana dependería de la reproducción de normas homogéneas de escritura a la hora de producir y enviar cartas, instrucciones y otros documentos. El presente artículo analiza toda una serie de prácticas sociales organizadas y de técnicas de escritura que estructuraron la comunicación jesuita durante las primeras décadas de existencia de la Compañía. La circulación y difusión de noticias manuscritas desempeñó entonces una función de enorme importancia a la hora de consolidar normas de comunicación. Se plantea así que la circulación de la información dentro de la orden estuvo determinada por prácticas materiales, sociales y culturales específicas que se desarrollaron sobre todo en el seno de los colegios jesuitas.
\end{abstract}

Palabras clave: Compañía de Jesús, escritura, cultura manuscrita, noticias, redes de noticias, Juan Alfonso de Polanco, comunicación, colegios jesuitas, información, cartas edificantes

\section{The Chancery in the College: the production and circulation of Jesuit texts in the sixteenth century}

\begin{abstract}
The circulation of letters, instructions, and news played an important role in the expansion of the Society of Jesus and in coordinating Jesuit endeavor across distance. Jesuit communication depended upon the replication of standardized norms of writing for the production and transmission of letters, instructions, and other documents. The article explores the cluster of organized social practices and techniques of
\end{abstract}

1 Abreviaturas utilizadas: Archivum Romanum Societatis Iesu (ARSI), Archivo Histórico Nacional, Madrid (AHN), Biblioteca de la Real Academia de la Historia, Madrid (BRAH), Archivo Provincial Histórico de Toledo, Alcalá de Henares (APHT), Monumenta Ignatiana. Epistolae et Instructiones, 12 tomos, Madrid, Augustinus Avrial, 1903-1911 (MI Epp.), Litterae quadrimestres ex universis praeter Indiam et Brasiliam in quibus aliqui de societate Jesu versabantur Romam missae, 7 tomos, Madrid-Roma, Augustinus Avrial-IHSI, 1894-1932 (LQ), Documenta Indica, ed. J. Wicki, 18 tomos, Roma, IHSI, 1948-88 (DI), Monumenta Brasiliae, ed. S. Leite, 5 tomos, Roma, IHSI, 1956-1968 (M Bras.), Archivum Historicum Societatis Iesu (AHSI). 
writing that structured Jesuit communication in the first decades of the order's history. In this period the circulation and dissemination of hand-written newsletters played an important function in consolidating norms of communication. It is suggested that the flow of information within the Society was shaped by specific material, social, and cultural practices localized in a highly concentrated fashion within the Jesuit colleges.

Key words: Society of Jesus, writing, manuscript culture, news, news networks, Juan Alfonso de Polanco, communication, Jesuit colleges, information, edifying letters

La circulación de cartas, instrucciones y noticias desempeñó un papel fundamental en la expansión de la Compañía de Jesús y en la coordinación a distancia de los esfuerzos jesuitas. Veinte años después de su fundación en Roma, en 1540, la orden se había extendido por toda Europa y alrededor del mundo. El peso que tuvo la comunicación dentro de la Compañía, particularmente para la organización y la divulgación de las misiones en Asia y en el Nuevo Mundo, es un capítulo bien conocido de la Historia Moderna $^{2}$. El flujo constante de información fue esencial además para el gobierno de la Compañía, pues permitió que las iniciativas jesuitas se desarrollasen con un grado extraordinario de cohesión y de uniformidad ${ }^{3}$. Como han mostrado algunos trabajos recientes, a la hora de estudiar la historia de la comunicación jesuita en sus primeros tiempos no basta con trazar el modelo que determinó el intercambio de escritos entre Roma y las periferias provinciales ${ }^{4}$. Lo cierto es que el lugar que ocupó la escritura en el seno de la Compañía se revela particularmente importante cuando consideramos los múltiples objetivos que perseguía la comunicación jesuita. La escritura desempeñaba numerosas funciones psicológicas, pastorales y espirituales que no se distinguían fácilmente de los usos administrativos de la información ${ }^{5}$. En estas páginas, pretendemos así examinar el conjunto de prácticas sociales organizadas y de técnicas

2 Véase, por ejemplo, Correia-Afonso, J.: Jesuit Letters and Indian History 1542-1773, BombayOxford, Oxford University Press, 1969; Harris, S.: "Confession-Building, Long-Distance Networks, and the Organization of Jesuit Science”, Early Science and Medicine, 1 (1996), pp. 287-318; CASTELnAU-L'EstoIle, C: Les Ouvriers d'une Vigne stérile. Les jésuites et la conversion des indiens au Brésil 1580-1620, Lisboa-París, Centre Culturel Calouste Gulbenkian-CNCDP, 2000; LABORIE, J.-C.: Mangeurs d'homme et mangeurs d'âme. Une correspondance missionnaire au XVIe, la lettre jésuite du Brésil, 1549-1568, París, Honoré Champion, 2003; Loureiro, R. M.: Na Companhia dos libros. Manuscritos e impressos nas missões jesuitas da Ásia Oriental 1540-1620, Macao, Universidade de Macau, 2007; Hsia, F.: Sojourners in a Strange Land: Jesuits and their Scientific Missions in Late Imperial China, Chicago, Chicago University Press, 2009, pp. 13-29.

3 Véase Friedrich, M.: "Government and Information-Management in Early Modern Europe. The Case of the Society of Jesus (1540-1773)", Journal of Early Modern History, 12 (2008), pp. 539-563.

4 Para la relación entre los jesuitas alemanes con Roma véase Friedrich, M.: Der lange Arm Roms? Globale Verwaltung und Kommunikation im Jesuitenorden 1540-1773, Frankfurt-Nueva York, Campus, 2011. Para los patrones de comunicación, frecuentemente desiguales, entre Alemania, Asia y México, véase CLossEY, L.: Salvation and Globalization in the Early Jesuit Missions, Cambridge, Cambridge University Press, 2008.

5 Véase Županov, I.: Disputed Mission: Jesuit Experiments and Brahmanical Knowledge in Seventeenthcentury India, Nueva-Delhi-Oxford-Nueva York, Oxford University Press, 1999, sobre todo, pp. 103 y ss.; Palomo, F.: "Corregir letras para unir espíritus. Los jesuitas y las cartas edificantes en el Portugal del siglo XVI", Cuadernos de Historia Moderna. Anejos, 4 (2005), pp. 57-81; ID.: "Misioneros, libros y cultura escrita en Portugal y España durante el siglo XVII", en C. Castelnau-L'estoile y otros (eds.): Missions d'évangélisation et circulation des savoirs (XVIe-XVIIIe siècle), Madrid, Casa de Velázquez, 2011, pp. 131- 
de escritura que estructuraron la comunicación dentro de la Compañía durante las primeras décadas de su historia.

La comunicación jesuita se basaba en la reproducción de normas estandarizadas de escritura para la producción y la transmisión de cartas, instrucciones y otros documentos. A pesar de la importancia reconocida a la comunicación escrita dentro de la orden, el trabajo propiamente manual que realizaron determinados sujetos, así como las redes institucionales que sustentaron la tarea de copia y transmisión de los "papeles jesuitas", continúan siendo aspectos poco estudiados. En este sentido, lo que el presente artículo plantea es que la circulación de la información dentro de una organización geográficamente tan dispersa como la Compañía estuvo determinada por prácticas materiales, sociales y culturales específicas, que, en buena medida, se desarrollaron en los colegios jesuitas.

El colegio era el eje de la red organizativa de la Compañía. Si bien las escuelas jesuitas han sido reconocidas desde hace mucho como poderosas instituciones de formación cultural, se ha prestado poca atención al papel más amplio que jugaron dentro de la orden ${ }^{6}$. En realidad, durante la época aquí estudiada, el grueso de los establecimientos ignacianos eran colegios y no casas profesas o casas de novicios. Los colegios servían como punto de contacto con las comunidades locales, justificaban la presencia continua de la orden en el paisaje urbano y funcionaban como imán a la hora de atraer patronazgos. Eran asimismo base para las iniciativas pastorales y permitían el desarrollo de misiones de interior en las áreas rurales. La posición que ocuparon los colegios en la formación de los jesuitas fue asimismo crucial, ya que proporcionaban a los estudiantes jesuitas las capacidades intelectuales, sociales y pastorales que exigía su ministerio a través de la enseñanza formal, del ejemplo y de la experiencia ${ }^{7}$. En términos de formación intelectual, la enseñanza asentaba sobre toda una batería de ejercicios de lectura, de anotación y de composición escrita ${ }^{8}$.

Los colegios constituían además nodos estables por medio de los cuales coordinar la comunicación a distancia. Algunos de ellos, estratégicamente situados, funcionaron como centros principales de comunicación interregional. Los rectores de los colegios, que informaban regularmente por escrito a los superiores provinciales y a

150; Nelles, P.: "Seeing and Writing: the Art of Observation in the Early Jesuit Missions", Intellectual History Review 20 (2010), pp. 317-333.

6 Desde los trabajos de O'Malley, J.: Los primeros jesuitas, Bilbao-Santander, Mensajero-Sal Terrae, 1995, pp. 249-298 y GiaRD, L. (ed.): Les Jésuites à la Renaissance: système éducatif et production du savoir, París, PUF, 1995, han proliferado los estudios locales. Véase la panorámica sobre los trabajos más recientes de GrendLeR, P. F.: "Jesuit Schools in Europe. A Historiographical Essay", Journal of Jesuit Studies 1 (2014), pp. 7-25.

7 Sobre el modo en el que los colegios contribuyeron a la formación misionera, véanse GreER, A.: Mohawk Saint: Catherine Tekakwitha and the Jesuits, Oxford, Oxford University Press, 2005, pp. 59-88; BrockEY, L.: Journey to the East: the Jesuit Mission to China, Cambridge (Massachussets), Harvard University Press, 2007, pp. 207-242.

8 Véase el estudio clásico de Codina Mir, G.: Aux sources de la pédagogie des Jésuites: le "modus parisiensis", Roma, IHSI, 1968. Sobre las instrucciones para escribir y tomar notas, NelLes, P.: "Libros de papel, libri bianchi, libri papyracei. Note-Taking Techniques and the Role of Student Notebooks in the Early Jesuit Colleges", AHSI, 76 (2007), pp. 75-112. Otra aproximación a las prácticas de escritura en los colegios en VAN DAMME, S.: "Écriture, institution et société: le travail littéraire dans la Compagnie de Jésus en France (1620-1720)", Revue de synthèse, 4a ser., 2-3 (1999), pp. 261-283. 
Roma, contaron frecuentemente con la ayuda de secretarios formales o informales que reunían la información y preparaban los borradores de la correspondencia. Otros jesuitas estaban encargados de copiar cartas, instrucciones, textos devocionales y pedagógicos, así como noticias. A este contexto hace referencia el título del presente artículo. La imagen de una "chancillería en colegio" viene de una queja acerca de Antonio de Araoz, el primer superior de la provincia castellana de la orden. Araoz tuvo un papel muy destacado en la introducción de la Compañía de Jesús en España, actuando como intermediario en las relaciones con la corte española. Residió de modo intermitente en el colegio jesuita de Valladolid y fue figura central en el intercambio de información entre los establecimientos jesuitas en España, la corte y Roma. En 1558, se informaba de que, durante los periodos en que Araoz estaba en Valladolid, "no pareçe este collegio [de] religión, sino chancillería". Esta crítica trataba sin duda de evocar la figura de un personaje inmerso en asuntos seculares, contraria a la misión religiosa de la Compañía. No obstante, la noción de "chancillería en colegio" no deja de ser un contrapunto útil a partir del cual analizar el modo en que los colegios favorecieron la reproducción de normas estandarizadas de comunicación escrita dentro de la orden.

La red de información jesuita tenía tres rasgos particulares: los flujos eran abundantes, seguían un ritmo regular y operaban a corta, media y larga distancia. El surgimiento de esta red no fue accidental. La práctica de la escritura en el seno de la orden se ordenó y coordinó cuidadosamente. El arquitecto que puso las bases de lo que habría de ser la circulación de la información dentro de la orden fue Juan Alfonso de Polanco, secretario en Roma durante más de veinticinco años ${ }^{10}$. Entre 1547 y 1573, controló la comunicación jesuita en Europa y en el mundo. Cuando asumió el puesto de secretario en 1547, trató de poner orden en el sistema informal de comunicación que había surgido a principios de esa década. Al tiempo que la Compañía se expandía, la red jesuita fue cambiando, en ocasiones de modo gradual y en otras de manera abrupta y dramática. El alcance de la expansión durante los primeros años de la Compañía fue significativo y si, a mediados de la década de 1540, sólo existía un puñado de colegios, en el momento de la muerte de Ignacio, en 1556, había más de cuarenta, y durante los veinte años siguientes se fundarían cien colegios más y otros muchos establecimientos. La actividad misionera en Europa y fuera de Europa incrementó el número de cartas, instrucciones e informes. Ciertamente, en áreas como el norte de

\footnotetext{
9 Carta de Juan Bautista de Ribera a Diego Laínez (26-5-1558), en Lainii Monumenta. Epistolae et acta patris Jacobi Lainii, 8 vols., Madrid, Typ. G. López del Horno, 1912-1917, vol. 3, p. 296. Para Araoz y su trato con la corte española, véase Zubillaga, F. "El Procurador de la Compañía de Jesús en la Corte de España", AHSI, 16 (1947), pp. 1-55; para el contexto general, Burrieza SÁnchez, J.: "La Compañía de Jesús y la defensa de la monarquía hispánica", Hispania Sacra, 60 (2008), pp. 181-229.

10 Sobre Polanco, y para una bibliografía más extensa sobre el personaje, véase GARCíA DE CASTRO, J.: Polanco. El humanismo de los jesuitas (1516-1576), Bilbao-Santander-Madrid, Mensajero-Sal TerraeUniversidad Pontificia de Comillas, 2012; Burrieza SÁnchez, J.: "Polanco, Juan Alfonso", en Diccionario Biográfico Español, Madrid, RAH, 2013, vol. 41, pp. 861-863.
} 
Italia o Castilla, había una mayor concentración de colegios que estaban relativamente próximos los unos de los otros, pero, en general, la dispersión geográfica de estos establecimientos desafiaba los límites de la comunicación en la Edad Moderna. Los jesuitas de París (desde 1540), Coímbra (1542), Goa (1542), Valencia (1544), Sicilia (1548), Brasil (1549), Viena (1551) y Praga (1556) comunicaban todos ellos de forma regular con Roma. Esto no era, por supuesto, algo exclusivo de la Compañía de Jesús. Roma siempre fue el centro administrativo del catolicismo occidental y la comunicación habitual entre Roma y las partes era un rasgo común de la administración de otras órdenes religiosas y de las varias instancias de la curia papal. Lo que quizás fue único en los jesuitas -aunque falta un estudio comparativo que aborde esta cuestión- fue la naturaleza altamente centralizada de la orden y el intento de imponer un alto grado de uniformidad a la comunicación, tanto en la forma como en la frecuencia. En el caso jesuita, el crecimiento constante de la Compañía en sus primeras décadas impuso fuertes exigencias sobre los flujos de información en términos de volumen, frecuencia y distancia.

Los papeles estaban en constante tránsito dentro de la Compañía: informes sobre el personal, notas de carácter financiero, documentos legales, cartas, noticias, instrucciones, reglas, y cartas patentes corrieron regularmente entre los establecimientos jesuitas. Aquí nos limitaremos a un único tipo de documento: la carta edificante. Estas misivas para consuelo espiritual daban cuenta de la vida diaria en los colegios $\mathrm{y}$ del trabajo pastoral en las misiones urbanas y rurales de Europa y en ultramar ${ }^{11}$. Las cartas edificantes circularon ampliamente entre los religiosos de la Compañía y, a pesar de que tenían poco que ver con el gobierno o la administración, se situaban de lleno en el núcleo ideológico de su estrategia de comunicación, pues describían la experiencia jesuita y proporcionaban ejemplos reales de la práctica apostólica de los ignacianos ${ }^{12}$. En las Constituciones de la orden, el intercambio regular de cartas se describía, juntamente con la obediencia (lo que no deja de ser significativo), como uno de los mecanismos principales para la "unión de los ánimos"'. En la práctica, la producción y la circulación de cartas edificantes hicieron las veces de otros mecanismos de formación identitaria y de unidad corporativa propios de un grupo social numéricamente pequeño pero geográficamente disperso. A la hora de mostrar a los miembros de la Compañía lo que significaba ser jesuita, las cartas sólo fueron superadas en importancia por los Ejercicios espirituales y los propios ignacianos fueron bien conscientes de su valor psicológico. En 1559, los jesuitas de Granada escribían: "Mucho nos consolamos con las buenas nuevas que tenemos de lo que nuestro señor se digna obrar por la compañía en todas partes" ${ }^{14}$. En realidad, era un sentimiento que se evocaría constantemente en la correspondencia jesuita.

11 Véase Friedrich, M.: "Circulating and Compiling the Litterae Annuae: Towards a History of the Jesuit System of Communication", AHSI, 77 (2008), pp. 3-40; DANIELUK, R.: "Ob communem fructum et consolationem: la genèse et les enjeux de l'historiographie de la Compagnie de Jésus", AHSI, 75 (2006), pp. 29-62; LABORIE, op. cit. (nota 2).

12 Palomo, op. cit. (nota 5, 2005).

13 Constitutiones Societatis Jesu, 3 vols., Roma, IHSI, 1934-1948, vol. 2, pp. 608-620.

14 ARSI, Hisp. 96, fol. 370r. 
Ya en 1550, la versión preliminar de las Constituciones señalaba que el conocimiento de "las nuevas y informaçiones que de unas y otras partes vienen" facilitaría "la unión de los miembros entre sí y con la cabeça". Era por tanto responsabilidad de los superiores provinciales asegurarse "cómo en cada parte se pueda saber de las otras lo que es para consolaçión y edificaçión mutua en el S[eñ]or N[ues]tro". ${ }^{15}$ Lo que aún no estaba claro en 1550 era cómo iba a funcionar el sistema de intercambios. En las páginas siguientes observaremos con detalle los pasos que Polanco dio en sus primeros años como secretario para intentar, no siempre con éxito, poner orden en la circulación de papeles dentro de la Compañía.

Siguiendo una práctica común en el siglo XVI, los jesuitas compartían noticias de modo rutinario. La amplia circulación de cartas -completas o partes de ellas, de modo individual o en remesas- constituía un elemento esencial de la naciente cultura de la noticia en la Europa moderna. En este sentido, la correspondencia epistolar dentro de la Compañía respondía a un patrón reconocible de intercambio de noticias manuscritas que surgió en las décadas centrales del siglo XVI ${ }^{16}$. Entre los jesuitas, la comunicación funcionaba a dos niveles. Un primer nivel era interno e incluía la correspondencia administrativa, las instrucciones y otros instrumentos de gobierno, así como las cartas edificantes, concebidas para ser difundidas ampliamente dentro de la Compañía. El segundo nivel era externo. Desde muy temprano, las noticias sobre las actividades de los jesuitas demostraron ser una beneficiosa fuente de capital social y cultural, de modo que ellos mismos hicieron circular cartas edificantes (en ocasiones, bajo forma de ediciones o en versiones purgadas) entre patronos y otros "amigos" de la Compañía. Tal y como Ignacio explicó al portugués Simão Rodrigues, las cartas edificantes debían poder mostrarse a todos, a "grandes, medianos y pequeños, y a buenos y a malos"17.

Para que las noticias resultasen efectivas era necesario controlarlas. En 1542, Ignacio prometió que escribiría a toda la Compañía al menos una vez al mes y que cada tres meses haría circular noticias y copias de cartas escritas por otros ${ }^{18}$. Se ha conservado un puñado de misivas enviadas desde Roma a mediados de la década de 1540 y resulta claro que, en torno a 1543, el patrón se había modificado y que Roma

15 Constitutiones (nota 13), vol. 2, pp. 618-20.

16 Véase Bouza, F.: Corre manuscrito. Una historia cultural del Siglo de Oro, Madrid, Marcial Pons, 2001, pp. 137-173; PIEPER, R.: "Cartas de nuevas y avisos manuscritos en la época de la imprenta. Su difusión de noticias sobre América durante el siglo XVI", Cuadernos de historia moderna. Anejos, 4 (2005), pp. 8394; Infelise, M.: Prima dei giornali. Alle origini della pubblica informazione, Roma-Bari, Laterza, 2002; Bethencourt, F. y Egmont, F. (eds): Cultural exchange in Early Modern Europe, vol. 3: Correspondence and Cultural Exchange in Europe, Cambridge, Cambridge University Press, 2007; PetitJean, J.: "Mots et pratiques de l'information. Ce que aviser veut dire (XVI ${ }^{-}-\mathrm{XVII}^{\mathrm{e}}$ siècles)", Mélanges de l'École française de Rome, 122 (2010), pp. 107-121.

17 Carta de Ignacio a Simão Rodrigues (1-11-1542), MI Epp., t. 1, p. 235.

18 Carta de Ignacio a Pierre Favre (10-12-1542), MI Epp., t. 1, p. 238. 
enviaba noticias de la orden cada cuatro meses ${ }^{19}$. En buena medida, se trataba de una red informal que dependía de los vínculos sociales existentes entre Ignacio y el reducido grupo de los primeros jesuitas.

La principal innovación de Polanco fue imponer un orden temporal al ritmo de la comunicación jesuita. En julio de 1547 envió una serie detallada de instrucciones sobre cómo escribir a Roma, en la que se indicaba que los superiores jesuitas de Italia y Sicilia debían escribir una vez a la semana, mientras que los del resto de Europa debían hacerlo una vez al mes "haya ó no aya que escribir cosas nuevas, aya ó no aya correo". Los jesuitas que estaban fuera de Europa debían escribir una vez al año. Los asuntos de negocios o las cartas importantes debían mandarse por duplicado o, incluso, por triplicado ${ }^{20}$. Los criterios de intercambio eran diferentes, pues Roma se comprometía a responder a los jesuitas de Italia una vez al mes y a los del resto de Europa únicamente cada cuatro meses ${ }^{21}$. Polanco mantuvo así el uso establecido de mandar noticias desde Roma tres veces al año ${ }^{22}$.

En este sentido, en 1547, se introdujo otra novedad que tendría consecuencias duraderas. Imitando la costumbre romana, Polanco pidió a los superiores jesuitas que escribiesen a Roma cada cuatro meses, en enero, mayo y septiembre. Estas cartas debían ofrecer un resumen de la correspondencia ordinaria enviada durante los cuatro meses precedentes. "Porque se pierden muchas cartas - explicaba Polanco- cada quatro meses se escriba una, donde se dirán en summa las cosas que son de edificatión desde la otra embiada quatro meses antes" ${ }^{23}$. Este tipo de cartas acabaría por ser conocido como letra de cuatro meses, letra cuatromestre o, más habitualmente, como quadrimestre. A menudo se hacía referencia a ellas simplemente como nuevas. Las quadrimestres, como veremos más adelante, evolucionaron hacia el que quizás sea el documento jesuita que mejor se conoce: la carta anua.

Al inicio, el mandato de elaborar quadrimestres fue prácticamente ignorado. Si bien se han conservado algunas cartas edificantes para el periodo 1547-1549, ninguna corresponde al tipo de sumarios que Polanco ordenó enviar tres veces al año. Las nuevas de carácter edificante continuaban fluyendo hacia Roma como parte de la correspondencia ordinaria de la Compañía, que Polanco copiaba y redirigía diligentemente. "De las cosas de edificatión, en particular, sería cosa luenga scrivirlas", escribió Polanco a Gandía y Valencia, al tiempo que indicaba que "de otras partes yrán nuevas con este mesmo enboltorio" 24 . A través de los registros de la correspondencia saliente se aprecia claramente que Polanco y sus ayudantes trabajaban de modo sistemático. Polanco actuaba como intermediario, filtrando y transmitiendo las noticias

\footnotetext{
19 Véase, por ejemplo, MI Epp., t. 1, pp. 248-249.

20 Polanco, J.: "Reglas que deven observar acerca del escribir los de la Compañía que están esparzidos fuera de Roma" (27-7-1547), MI Epp., t. 1, pp. 548-549.

21 Carta de Polanco a Antonio Araoz (27-5-1547), MI Epp., t. 1, p. 550.

22 Polanco, J.: "De offiçio del secretario", en Scaduto, M.: "Uno scritto ignaziano inedito. Il De offiçio del secretario del 1547”, AHSI 29 (1960), p. 322.

23 Polanco, "Reglas", op. cit., (nota 20), pp. 548-549.

24 Carta de Polanco a Andrés de Oviedo, en Gandía, y a Diego Mirón, en Valencia (24-7-1549), MI Epp., t. 2, pp. 490-491.
} 
de unos centros de la red jesuita a otros y manteniendo un registro de qué noticias debían enviarse a cada lugar ${ }^{25}$.

Exceptuando estos registros sumarios que Polanco elaboró en Roma, quedan pocos testimonios materiales sobre la circulación de noticias en estos primeros años. En este sentido, la colección que se conserva de cartas del colegio jesuita de Alcalá encierra particular interés, ya que en ella se conservan algunos ejemplos excepcionales de las primeras noticias manuscritas que circularon dentro de la Compañía ${ }^{26}$. Fundado en 1546, el colegio de Alcalá se incorporó inmediatamente a la red de información jesuita y recibió copias de cartas enviadas a Roma desde Bolonia y Lovaina en 1546 y $1547^{27}$. Entre 1547 y 1550 , Alcalá recibió con regularidad copias o extractos de las cartas enviadas a Roma por los jesuitas de otros lugares de Italia. Las noticias escritas en italiano se traducían al español en Roma antes de ser enviadas y se mandaban habitualmente en remesas ${ }^{28}$. En marzo de 1548, por ejemplo, Polanco envió noticias de los colegios jesuitas de Florencia, Bolonia, Ferrara, París y Sicilia ${ }^{29}$. La colección de Alcalá y las fuentes romanas muestran que, si bien el propio Polanco dinamizó las noticias en esos años, pocos colegios componían quadrimestres. Todo apunta a que el grado de cumplimiento fue mínimo.

Todo cambió en enero de 1550, cuando Polanco e Ignacio enviaron una instrucción que obligaba estrictamente a todos los superiores jesuitas a mantener el calendario de correspondencia exigido en 1547 . Esto afectaba tanto a la correspondencia administrativa ordinaria como a las quadrimestres. La carta indicaba sencillamente que "no se observava lo que se avía encomendado del scrivir", y continuaba señalando que "quanto á las nuevas que debían ynbiarse cada 4 meses de todas partes, sería menester se observase; si no, también por obedientia se ordenará" ${ }^{30}$. En febrero, se envió una segunda instrucción, referente únicamente a las quadrimestres. En ella, Polanco reiteraba la importancia del intercambio de noticias para mantener la cohesión de la Compañía, señalaba pacientemente que ya antes se habían mandado instrucciones para que los superiores locales escribiesen a Roma cada cuatro meses y explicaba que el plan era copiar esas cartas en Roma y reenviarlas a los jesuitas de aquellas regiones que no podían comunicarse fácilmente entre sí. A continuación, Polanco

25 Polanco, "De offiçio del secretario", op. cit., (nota 22), p. 327.

26 Varia historia rerum a societate gestarum intra Europam, APHT, Ms. C-201/1-2. Estos tomos contienen tanto originales como copias contemporáneas de las cartas enviadas al colegio de Alcalá. Un tercer tomo de cartas enviadas desde las misiones de ultramar se recopiló bajo el título de Varia historia rerum a Societate Iesu gestarum extra Europam, APHT, Ms. C-201/3. Las cartas (muchas de ellas autógrafas) de Ignacio, Pierre Favre, Francisco Javier y otros están recogidas en un volumen aparte, hoy día en la Biblioteca del Palacio Real de Madrid, Ms. II/2408. Todos estos tomos fueron reunidos por Cristóbal de Castro a finales del siglo XVI para preparar su Historia del Colegio Complutense de la Compañia de Jesús (1600), APHT, Ms. C-208. Se confeccionó además otro volumen independiente de cartas de las misiones de ultramar, copiadas de modo continuado por varias manos diferentes para su lectura en el refectorio de Alcalá. Este volumen, copiado posiblemente en la década de 1580 y con añadidos hasta 1590, se encuentra hoy en BRAH, Ms. 9/2663, con un índice y números de página escritos con letra de Castro.

27 APHT, Ms. C-201/1, fols. 59r-83r, 99r, 111r.

28 Ibidem, fols. 55r-58v; extractos parciales en $L Q$ t. 1, pp. 122-123, 132, 154.

29 Carta informativa de marzo de 1548, APHT, Ms. C-201/1, fols. 115r-123r; Nadal (Mesina), Abril de 1549 , fol. 55 r (véase $L Q$ t. 1, p. 152).

30 Polanco, J.: “Obedientia del scrivir” (13-1-1550), MI Epp., t. 2, p. 647. 
iba directamente al grano, indicando que eran pocos y excepcionales los que habían cumplido. De resultas, en Roma, habían tenido que dedicar mucho tiempo y trabajo a extraer pasajes de la correspondencia entrante, traducir ese material de un sinfín de lenguas y enviar copias a multitud de lugares distintos. En un tono crítico, Polanco indicaba que habría sido mucho más fácil que, desde cada lugar, se hubiese escrito a Roma y no que, desde Roma, se escribiese a todos en cada provincia. No obstante, él había asumido esa difícil tarea, a pesar de que -insistía- habría resultado más fácil si la hubiesen acometido por sí mismas las provincias. Pero la experiencia venía mostrando - continuaba- que la situación era insostenible y que lo sería aún más a medida que la Compañía se fuese expandiendo. Los superiores locales y todos los jesuitas en misión recibieron así la orden, bajo estricta obediencia, de observar la obligación de escribir a Roma tres veces al año, comenzando en mayo de $1550^{31}$. Rebajando un poco el tono, Polanco recordó amablemente a los jesuitas que un texto en latín permitiría aliviar la presión sobre la curia de Roma, ya que las cartas enviadas en la lengua vernácula de una región debían ser traducidas antes de ser redistribuidas. Sin embargo, no insistió demasiado en ello. Sin duda, era ya suficientemente difícil obtener resultados en vernáculo, por lo que se limitó a indicar que "en qualquiera lengua bastará" 32 .

Si bien el ideal ignaciano de "obediencia ciega" es una faceta bien conocida de la cultura jesuita, una mención así de directa a la obediencia era en realidad poco habitual, sobre todo a nivel colectivo. El ejercicio de la obediencia en la Compañía era un proceso bastante complejo, que permitía adaptar las reglas e instrucciones a las particularidades del momento, la persona y el lugar; la esencia misma de la acomodación jesuita. La práctica de la obediencia permitía también la existencia de puntos de vista divergentes u opuestos ${ }^{33}$. En el caso de las quadrimestres, el historial de incumplimientos revela que, evidentemente, reinó una enorme confusión. Como hemos visto, en 1547, Polanco había afirmado que las quadrimestres eran una salvaguarda frente a las cartas que se perdían en el camino y puede que, vistas desde esta óptica, muchos jesuitas las considerasen innecesarias. Es más que probable que, en 1547, el mismo Polanco no tuviese una idea clara de cómo debían circular las noticias, pero, después de tres años como secretario, el trabajo de seleccionar, copiar y reenviar noticias se había vuelto claramente insoportable para la curia de Roma.

31 Cabe destacar la nula atención que se ha prestado a esta instrucción. PolAnCO, J.: "Obedientia scribendi" (7-2-1550), MI Epp., t. 2, p. 676: "Cum tamen hoc a paucis et raro curatum sit, magno temporis et laboris impendio, ex plurimis undecumque missis litteris excerpere ea, quae aliis comunicanda viderentur, et in varias linguas vertere, et pluribus exemplis ad plura loca mittere oportuit. Itaque cum tanto facilius esset singulis locis Romam, quam iis, quae Romae sunt, omnibus aliis provinciis scribere, diligentius tamen qui hic sumus difficiliora, quam qui foris faciliora, in hac parte prestitimus. Sed re vera edocti sumus ipsa experientia, inter tam multas, quibus hic distinemur, occupationem hanc tolerabilem non esse, eo minusque in dies futuram, quo magis res Societatis divina bonitas promovebit".

32 Ibidem, p. 677; Polanco, "Obedientia del scrivir", op. cit. (nota 30), p. 647.

33 A este respecto, véase Gioia, M.: “Obediencia”, en Diccionario Histórico de la Compañía de Jesús, 4 vols., Roma-Madrid, IHSI-Universidad de Comillas, 2001, vol. 3, pp. 2852-2855; Mostaccio, S.: “"Perinde ac si cadaver essent'. Les Jésuites dans une perspective comparative: la tension constitutive entre l'obéissance et le 'representar' dans les sources normatives des réguliers", Revue d'histoire ecclésiastique, 105 (2010), pp. 44-73; y los ensayos reunidos en Alfieri, F. y Ferlan, C. (eds.): Avventure dell'obbedienza nella Compagnia di Gesù. Teorie e prassi fra XVI e XIX secolo, Bolonia, Il Mulino, 2012. 
Las quejas de Polanco no se referían al trabajo de copia. Lo que mayor tiempo consumía era revisar la correspondencia ordinaria y seleccionar el material digno de convertirse en noticia, y este era el trabajo que Polanco quería que pasasen a realizar los colegios. A partir de ese momento, al menos en teoría, Roma tendría apenas un papel de centro de copia y reenvío de la correspondencia. Lentamente al comienzo y de modo más estable después, los jesuitas empezaron a escribir como se les había pedido. En mayo y septiembre de 1550 llegó un puñado de cartas, y en enero y mayo del año siguiente escribieron algunos colegios más. En junio de 1551, Polanco y sus asistentes eran capaces de hacer circular quadrimestres de modo regular. A los jesuitas de España y de París les enviaron noticias de Foligno, Palermo, Mesina e Ingolstadt, y los de París recibieron además noticias de Salamanca ${ }^{34}$. El 20 de junio se enviaron a Mesina las noticias de Ingolstadt, París y Gandía; una semana más tarde las de Alcalá y Foligno, a comienzos de julio las de Venecia y Bolonia, y las de Salamanca a mediados de agosto. Llegado enero de 1552 Polanco sentía sin duda que el sistema tenía cimientos sólidos. Una carta suya a los jesuitas de Alcalá iba salpicada de noticias de los colegios italianos e indicaba que las quadrimestres les darían más detalles al respecto ${ }^{35}$.

Las quadrimestres, por tanto, circulaban ahora bajo la bandera de la obediencia. La directiva de Polanco de 1550 se conocería como la "Obediencia del scrivir". Cuando ésta se envió a los colegios, en los registros de Roma se hizo una sencilla anotación: "una obediençia". Aludir al cumplimiento se convirtió en sello característico de las quadrimestres, en las que era habitual mencionar "la santa obediencia". Una carta típica de este género de misivas, enviada desde Alcalá, comenzaba con un "para cumplir la obediencia" ${ }^{36}$ y otra, desde Monterrey, empezaba señalando que "Por obedientia del Padre rector dare a V.P. relación de las cosas que nuestro señor ha obrado en este collegio" ${ }^{37}$.

No se trataba a pesar de todo de un sistema etéreo, sino de una red social que dependía de la difusión y reproducción de prácticas gráficas, materiales y textuales de escritura. La divulgación y apropiación de estas normas era tan importante como el contenido de las propias cartas y pese a que la escritura se convirtió en algo rutinario, fueron necesarias repetidas instrucciones acerca de cómo y cuándo escribir. La "Obedençia de scrivir" circuló ampliamente. En 1551 se enviaron nuevamente instrucciones que resumían las Reglas de 1547, y en 1552 se despachó una nueva instrucción relativa a la elaboración de las quadrimestres y de los catálogos del personal ${ }^{38}$. Una versión de-

\footnotetext{
34 MI Epp., t. 3, pp. 557, 558, 564, 570, 584, 613.

35 MI Epp., t. 4, pp. 60; p. 260 para un consejo parecido a Araoz en junio de 1552.

$36 L Q$, t. 1, p. 617.

$37 L Q$, t. 5, p. 535.

38 Debido al carácter sumario que Polanco dio entonces al registro de la correspondencia saliente, la mayoría de estas instrucciones se conocen sólo por referencias indirectas o por breves indicaciones en los propios registros: "Obediençia de scrivir" (29-5-1550), MI Epp. t. 3, p. 29; "Del modo de scrivere le nuove" (1551), ibidem, pp. 607, 624, resumida en pp. 667-668; "Modo di scrivere” (1552), MI Epp., t. 4, pp. 209, 213, 214, 241, resumida en p. 563.
} 
purada de las Reglas de 1547 aún seguía en circulación diez años después ${ }^{39}$. Polanco, además, enviaba habitualmente consejos, recordatorios y críticas ad hoc.

La experiencia jesuita en su conjunto o, como escribió Polanco, "todo el estado del negocio espiritual", era susceptible de ser considerado noticia. Para poner orden sobre los datos en bruto de esa experiencia, Polanco estableció criterios sobre aquello de lo que se debía informar. Aclaró que el material que debía incluirse en las quadrimestres podía dividirse en dos tipos: la vida interna de la Compañía y la interacción jesuita con el mundo exterior. La savia de las noticias jesuitas debía asentar por lo tanto en informes sobre las actividades de los religiosos ignacianos. Polanco facilitó una especie de cuestionario, un esquema en catorce puntos que especificaba las materias sobre las que debía informarse a Roma. Era necesario indicar el número de jesuitas que vivía en cada casa, si se habían admitido novicios desde el envío de la anterior quadrimestre y si había algún candidato que aspirase a unirse a la Compañía. También era noticia la vida educativa del colegio, en particular los acontecimientos públicos tales como oraciones, diálogos y certámenes. En lo referente a los contactos entre los jesuitas y la comunidad local, debían incluirse todas y cada una de las actividades pastorales: predicación, estudio de las escrituras, confesiones, ejercicios espirituales, pacificaciones, conversaciones informales y visitas a los hospitales y cárceles. Los actos de patronos y benefactores también eran de interés y "en general todo lo que un amigo querría saber de otro", escribió Polanco ${ }^{40}$.

A los jesuitas de las misiones de ultramar se les dieron instrucciones adicionales. En noviembre de 1547, Polanco explicó a Niccolò Lancillotto, rector del colegio de Goa, que el papa y otros miembros de la curia romana tenían un enorme aprecio por las noticias de la India. Se pidió a Lancilloto que informara - por extenso y de modo "diligente y ordenado" - no sólo sobre los jesuitas, sino también sobre el clima de la India y la dieta, las costumbres y las características de sus habitantes ${ }^{41}$. Una vez más, el cumplimiento de estas instrucciones fue desigual, y hubo que enviar nuevos recordatorios y peticiones de información más específica a Brasil y a la India ${ }^{42}$.

La formación de una identidad colectiva no podía ser sino un empeño colectivo. Se esperaba de los rectores de los colegios y de los superiores provinciales que reuniesen, filtrasen y transmitiesen la información tal como Polanco lo hacía en Roma. En lo que respecta a la recopilación de la información, el secretario de la Compañía recomendaba que cada colegio tuviese un memorial en el que, "en breve y por puntos", se anotasen las cosas según iban ocurriendo. Sobre la base del mismo, cabía seleccionar el material a utilizar a la hora de escribir a Roma. El propio Polanco mantenía un diario en el que documentaba "lo que Dios obra aquí en Roma". Quienes salían de la casa romana de la Compañía para "trabajar en la viña del señor" eran entrevistados a su regreso y cualquier cosa destacada se registraba en dicho memorial. Los secretarios que asistían a Polanco estaban encargados de obtener esa misma información de

39 Polanco, J.: "Regole dello scrivere" (1557), ARSI, Opp. NN 55, fols. 50r-54r.

40 Polanco, "Reglas", op. cit., (nota 20), pp. 544-546.

41 Carta de Polanco a Niccolò Lancillotto (22-11-1547), DI, t. 1, pp. 206-207.

42 Carta de Polanco a Gaspar Barzaeus (13-8-1553), DI, t. 3, p. 16 y (24-2-1554), p. 63; Carta de Polanco a Manuel da Nóbrega (13-8-1553), M Bras., t. 1, p. 520. 
los hermanos legos ${ }^{43}$. Polanco advertía de que las cosas debían escribirse a diario, según ocurrían ${ }^{44}$. En determinado momento, recomendó que fuesen personas adecuadas las que se encargasen de registrar la información sobre predicaciones, confesiones, ejercicios espirituales, paces y otras obras pías. El material para las quadrimestres podía obtenerse a partir de estos registros ${ }^{45}$. Al superior de la provincia de la India se le recordó que, a pesar de que sólo estaba obligado a escribir una vez al año a Europa, debía no obstante ir "notando los puntos quando ocurren" para posteriormente incluirlos en su carta ${ }^{46}$.

Lo más habitual era compilar las quadrimestres de modo colectivo. Refiriéndose al "modo que guardamos de hazer letras quadrimestres", Jerónimo Nadal aconsejó al colegio de Evora "ordenar que cada uno note todas las cosas de edificación que le acaescen, y escrivirlas quotidianamente". Pasados cuatro meses, se escogía a dos jesuitas para revisar los cuadernos de notas y seleccionar el material apropiado. El rector del colegio u otro superior supervisaban después el material, añadiendo o eliminando lo que les parecía oportuno ${ }^{47}$. Existían también otras fuentes. A los jesuitas que participaban en misiones interiores, por ejemplo, se les exigía que escribieran semanalmente a su superior y que enviaran quadrimestres al colegio más próximo ${ }^{48}$. Pese a que, nominalmente, las quadrimestres eran competencia del rector del colegio, con frecuencia eran otros quienes las escribían. Los profesores de humanidades y de retórica de los colegios se ocuparon habitualmente de esta tarea. Un rector llegó a avisar a Roma de que la carta llegaría con retraso "perché li autori stanno occupati in le loro classi" ${ }^{49}$.

Cuando las quadrimestres se recibían en Roma, Polanco las revisaba cuidadosamente y, en muchas ocasiones, las reducía para aligerar algo el trabajo de copia. "Non perda V.R. tempo in preamboli", avisaba Polanco a cierto jesuita, "perch' comummente si tagliano di qua" y lo mismo se hacía con los detalles superfluos de poca importancia ${ }^{50}$. Polanco intervenía también en cuestiones de vocabulario y de estilo, tratando de imbuir en las cartas lo que habitualmente se denominaba como "elocuencia religiosa" ${ }_{51}$. Era frecuente traducir las cartas al latín o al italiano, especialmente las de las misiones oceánicas. La copia de noticias fue también una empresa colectiva: en Roma algunos cuadernos compuestos a partir de aquellos extractos de correspondencia entrante dignos de convertirse en noticia, presentan marcas de al menos dieciséis

\footnotetext{
43 Polanco, "Reglas", op. cit., (nota 20), p. 549; ID., "De offiçio del secretario", op. cit., (nota 22), pp. 322 y 328.

44 Carta de Polanco a todos los superiores (131-1550), MI Epp., t. 2, p. 647: "Y entiendo scrivir nuevas de edificatión haziendo que se tome por memoria lo que ay de día en día, que sea de scrivir".

45 Polanco, J.: "Ratio scribendi" (1560), ARSI, Instit. 117, fol. 180v. Sobre la "Ratio" de 1560, trataremos más adelante.

46 Carta de Diego Laínez a Antonio de Quadros (Goa, 31-12-1560), Lainii Monumenta, op. cit. (nota 9), vol. 5 , p. 359 .

47 NAdAl, J.: "Avisos de diversas cosas utiles para el govierno", ARSI, Instit. 208, fol. 448r.

48 "Sumario de lo que se contiene en la carta de escrivir que vino de Roma" (Portugal, 1560), ARSI, Instit. 206, fol. 230v: "Los que van a predicar por la provincia, escrivan las nuevas de edificación al más cercano collegio que estuviere, para que se escrivan en las quadrimestres de aquel collegio".

49 ARSI, Ital. 107, fol. 136v.

50 MI Epp. t. 8, pp. 33-34.

51 Por ejemplo, MI Epp. t. 4, p. 209.
} 
copistas diferentes y las noticias que se enviaban desde Roma muestran igualmente rastros de múltiples manos ${ }^{52}$.

Pese a las resistencias iniciales a escribir quadrimestres, el sistema establecido por Polanco se incorporó gradualmente al ritmo de la comunicación jesuita. Aunque esto fue en parte resultado de las instrucciones del secretario de la Compañía, las cartas en circulación también sirvieron de modelo. La difusión regular de las quadrimestres supuso que los jesuitas pudiesen contar de forma habitual con nuevos ejemplos sobre los que modelar sus escritos. El efecto combinado de las indicaciones de Polanco y de la circulación de un repertorio de temas por medio de las quadrimestres, hizo que las noticias fuesen a menudo repetitivas. Historias sobre predicaciones, confesiones, comuniones, conversiones y pacificaciones fueron la norma común. La repetición de topoi familiares se convirtió en parte del ritual de escritura y de lectura de quadrimestres. A pesar de que pueda resultar obvio subrayarlo, debe tenerse en cuenta que las noticias jesuitas se leían como noticias: es decir, como parte de una fuente seriada de informaciones sobre la labor de la Compañía. Para una orden cuya identidad se basaba en un ethos de evangelización "en diversos lugares entre fieles y infieles", las historias globales sobre misionalización, ya fuesen de Goa o de Gandía, siempre eran relevantes ${ }^{53}$.

La difusión de las quadrimestres dependía de una red dinámica de publicación manuscrita y, en consecuencia, Roma se convirtió en un centro principal de transmisión de cartas. Aunque el volumen de copias realizadas por Polanco y sus asistentes para hacer circular las quadrimestres es sorprendente, no enviaron una copia de cada carta a todos los colegios. Para empezar, las noticias se compartían habitualmente a nivel regional. Las instrucciones solían indicar que las cartas a Roma debían ser compartidas, total o parcialmente, con los jesuitas vecinos ${ }^{54}$. En la curia de Roma se tenía el cuidado de no enviar noticias que, probablemente, ya se conocían a través de fuentes locales $^{55}$. La colección de cartas de Alcalá ofrece algunos indicios a este respecto: entre 1548 y 1557, se recibieron desde Coímbra, Salamanca, Gandía, Lisboa y Évora, noticias o cartas edificantes que estaban dirigidas tanto a otros colegios como a Roma $^{56}$.

Por medio del intercambio habitual de cartas e instrucciones a nivel regional, se establecieron canales locales de comunicación. Los rectores de los colegios de España y Portugal sólo escribían a Roma una vez al mes, pero informaban semanalmente

52 Véase, por ejemplo, ARSI, Epp. NN. 78; APHT, Ms. C-210/1, fol. 137r-151r.

$53 \mathrm{La}$ frase aparece con frecuencia en la documentación jesuita, como por ejemplo en Constitutiones (nota 13), vol. 2, p. 596. Sobre la identidad misionaria global de la orden, véase BRoGGIO, P.: Evangelizzare il mondo. Le missioni della Compagnia di Gesù tra Europa e America (secoli XVI-XVII), Roma, Carocci, 2004; CATto, M, Mongin, G. y Mostaccio, S. (eds.): Evangelizzazione e globalizzazione: le missioni gesuitiche nell'età moderna tra storia e storiografia, Roma, Dante Alighieri, 2010.

54 Polanco, "Reglas", op. cit., (nota 20), p. 546; ID., "Regole dello scrivere", op. cit., (nota 39), fol. 51 r.

55 Polanco, "Del offiçio del secretario", op. cit., (nota 22), p. 322.

56 APHT, Ms. C-210/1, fols. 127r, 129r, 133r, 155r, 165r, 330r, 349r, 407r, 445r y 454r. 
a sus superiores provinciales. Estos canales regionales se usaron para la difusión de noticias que llegaban de más lejos. En 1547, Polanco había explicado que, en el caso de las casas jesuitas vecinas, las noticias de Roma se mandarían únicamente a un lugar y, desde allí, se copiarían o se reenviarían al resto ${ }^{57}$. Un sistema radial de copia y transmisión de quadrimestres surgió de manera gradual a partir de las propias redes de intercambio locales. No se trataba de una estructura rígida. En realidad, el sistema evolucionó con arreglo a una lógica compleja que tenía en cuenta factores como la localización geográfica de cada colegio, las rutas de transporte existentes, las redes de contactos jesuitas y no jesuitas y los recursos de los colegios. En ocasiones, esta red coincidía con la estructura de gobierno de la Compañía, pero, en general, no lo hizo. A veces se enviaban varias copias de una misma carta a un colegio, al que se encomendaba que las remitiese a otros. En otros casos, se pedía a los jesuitas que copiasen quadrimestres y otras nuevas y las enviasen a los colegios cercanos. Pero lo más frecuente era pedir simplemente a los colegios que leyesen las cartas y, a continuación, las reexpidiesen a los establecimientos vecinos. El sistema, sobre todo, exigía la participación colectiva a la hora de copiar y hacer circular textos escritos a mano. El soporte manuscrito en el que corrían estas cartas edificantes ayudó a configurar a un nivel material los lazos sociales y espirituales que las cartas debían reforzar textualmente ${ }^{58}$.

Antes de llegar a España y Portugal, los envíos solían ir directamente de Roma a Génova, habitualmente por mar, vía Civitavecchia. El colegio de Génova, fundado en 1554, funcionó como un nexo de transmisión clave entre Roma y la península Ibérica. Las cartas aguardaban en Génova hasta que partiese algún barco en dirección a Barcelona, y el colegio de Barcelona actuaba como centro de distribución de las cartas que viajaban al resto de España. Nada indica que Génova o Barcelona funcionasen como centros de copia, sino que eran más bien nodos seguros de circulación dentro de una red de información jesuita que asentaba en puntos estructuralmente vulnerables. Los rectores de los colegios de estas ciudades portuarias importantes tenían acceso directo a correos, agentes informales (por lo común mercaderes) y al transporte. En 1549, Joan Queralt, rector del colegio de Barcelona, explicaba a Polanco que lo más sencillo era que Barcelona se ocupase de todo: "Acá siempre ay portadores, y se sabe, pienço yo, más á quienes se pueden dar y dirigir" 59 .

A partir de Barcelona las noticias se enviaban en dos direcciones. En primer lugar, dentro de Aragón, donde las cartas se mandaban hacia el interior, a Zaragoza, y a lo largo de la costa mediterránea, a los colegios de Valencia, Gandía y Murcia. A Valencia y Zaragoza se les encargaba frecuentemente que copiasen las cartas y las reenviasen a otros colegios, mientras que a Barcelona se le daban instrucciones de

\footnotetext{
57 Polanco, "Reglas", op. cit., (nota 20), pp. 546-547.

58 Acerca de la cultura manuscrita del periodo, véase Bouza, op. cit. (nota 16); Richardson, B.: Manuscript Culture in Renaissance Italy, Cambridge, Cambridge University Press, 2009.

59 Carta de Joan Queralt a Polanco (8-6-1549), en Epistolae Mixtae ex variis Europae locis, 5 vols., Madrid, Augustinus Avrial, 1899, vol. 2, p. 229. Véase Vila Despujol, I.: La Compañía de Jesús en Barcelona en el siglo XVI. El Colegio de Nuestra Señora de Belén, Madrid-Roma, Universidad Pontificia de ComillasIHSI, 2010, pp. 227-229.
} 
leer las noticias antes de volver a enviarlas ${ }^{60}$. Al oeste quedaba la densa constelación de colegios castellanos. Zaragoza se usaba habitualmente como lugar en el que copiar las cartas que debían transitar hacia los colegios de Valladolid, Alcalá y Madrid y más raro- hacia el de Valencia ${ }^{61}$. Valladolid, que, como hemos visto, sirvió de base a Araoz en estos años, actuaba como centro principal de distribución de cartas en Castilla. Al colegio se le encargaba con frecuencia copiar las nuevas (en una ocasión, las quadrimestres de Colonia, Ingolstadt y Lovaina en una sola remesa) que se enviaban a Burgos y Oñate al norte, a Medina del Campo y Salamanca al sudoeste, y a Madrid y Alcalá al sudeste ${ }^{62}$. Cuando, en lugar de enviarse desde Génova, las noticias y los despachos llegaban por tierra a través de Lyon, Burgos actuaba como centro a partir del cual difundir las cartas hacia el resto de España y Portugal ${ }^{63}$.

La provincia portuguesa ocupaba una posición única dentro de la red de comunicaciones de la Compañía, ya que toda la correspondencia de los jesuitas de Europa con los de Asia, África y Brasil pasaba a través de Lisboa ${ }^{64}$. Debido a los peligros de estos viajes marítimos a larga distancia, toda la comunicación escrita se enviaba normalmente en al menos tres o cuatro copias, utilizando diferentes barcos o "vías". A lo largo de las décadas de 1540 y 1550 los jesuitas del colegio de Coímbra, y después los de Lisboa, estuvieron encargados de copiar cartas, instrucciones y quadrimestres para mandárselas a los hermanos presentes en las posesiones portuguesas. A finales de la década de 1550, esto implicaba varias copias para los jesuitas de Brasil, África y Asia. Los colegios de Coímbra y Lisboa estaban también encargados de copiar las cartas de las misiones de ultramar para las provincias europeas. Además, las cartas escritas en portugués (que eran la mayoría) se traducían al español para que circulasen por los colegios de la península Ibérica. A Roma se enviaban regularmente copias en español y a veces en latín.

Es bien conocido que los jesuitas portugueses recurrieron a la imprenta para aliviar la tarea de copiar las cartas de las misiones ultramarinas y varias ediciones de cartas se publicaron en Coímbra en las décadas de 1550 y $1560^{65}$. Pero la imprenta, más que reemplazar la producción de copias manuscritas, apenas aumentó la circulación. No hay duda de que la imprenta contribuyó enormemente a la difusión de cartas de misión, en particular fuera de la Compañía, pero no todas las misivas se imprimieron e, incluso en el caso de aquellas que sí lo fueron, la imprenta simplemente redujo la

60 Por ejemplo, MI Epp., t. 3, p. 595 (1-8-1551), a Barcelona: "Che lega una letera de cose commune per Gandia, et le mandi a Valentia con altre lettere”; MI Epp. t. 4, p. 69 (2-2-1552); p. 164 (25-2-1552), a Barcelona: "Se ynbían todos los emboltorios para Castilla y Valencia y Çaragoça ... y leydas las nuevas, las ynbíen á Valencia".

61 MI Epp., t. 3, p. 627 (1-9-1551), a Zaragoza: "Che facia copiare le noue per Alcalá et Valentia, etc., mandando una altra copia a Valledolit".

62 Véase, por ejemplo, MI Epp., t. 3, p. 598 (1-8-1551) y p. 630, (1-9-1551); MI Epp., t. 4, p. 142 (2-21552): "Si ordina li mandino di Balladolid copie de alcune nove".

63 MI Epp., t. 5, pp. 673, 675; t. 6, pp. 304, 371.

64 Para una panorámica, véase FERRO, J. P.: “A epistolografia no quotidiano dos missionários jesuítas nos séculos XVI e XVII”, Lusitania sacra, 2ª ser., 5 (1993), pp. 137-158.

65 Sobre las ediciones impresas de las cartas, véase GARCIA, J. M.: “A epistolografia ultramarina dos jesuítas impressa em Portugal no século XVI", en Missionação portuguesa e encontro de culturas. Actas, 4 vols., Braga, Universidade Católica Portuguesa, 1993, vol. 3, pp. 123-33; PALomo, op. cit. (nota 5, 2005), pp. 73-74. 
escala de producción manuscrita, pero no la sustituyó. La colección de cartas de Alcalá, así como varias recopilaciones que se elaboraron en los colegios portugueses durante la década de 1560, están llenas de copias manuscritas de misivas que también circularon impresas. Algunas, incluso, son copias hechas a partir de las versiones en letras de molde ${ }^{66}$. Los jesuitas de Lisboa y Coímbra siguieron produciendo asimismo múltiples copias manuscritas de cartas e instrucciones procedentes de Roma y de los colegios europeos, destinadas a las misiones ultramarinas.

En el borrador final de las Constituciones jesuitas de 1556, Polanco intentó vincular la circulación de quadrimestres a la estructura administrativa de la orden. A los superiores locales y a los jesuitas en misión se les encomendaba enviar cuatro copias de cada carta a su superior provincial, dos en vernáculo y dos en latín. El provincial debía posteriormente enviar a Roma un ejemplar de ambas versiones junto con su propia carta, además de garantizar que las cartas de las casas jesuitas de su propia provincia se copiasen y circulasen localmente. En Roma, se debían hacer copias de las quadrimestres recibidas desde cada uno de los colegios, reenviando un ejemplar de cada carta a los provinciales. En lo que respecta a su circulación dentro de cada provincia, era nuevamente el superior el responsable de que se hiciesen copias para cada una de las casas ${ }^{67}$.

Si bien no hay ningún sistema de comunicación que funcione a la perfección, asumamos por un instante (como puede que Polanco hiciese en ocasiones) que el sistema jesuita operó de acuerdo con las directrices establecidas en las Constituciones. Aunque las casas y colegios más pequeños no solían escribir quadrimestres, a la altura de 1559, circularían habitualmente cartas de alrededor cincuenta casas jesuitas ${ }^{68}$. En esa fecha la Compañía contaba con trece provincias, incluyendo Portugal y las tres provincias españolas (Aragón, Castilla y Andalucía). Dependiendo de dónde se hubieran originado las cartas, en Roma se deberían producir entre seis y nueve copias de cada una. Esto nos daría un resultado aproximado de entre 900 y 1350 copias de quadrimestres hechas al año en Roma. Sin duda, el número real de copias fue considerablemente menor, pero incluso asumiendo una tasa de cumplimiento de cerca del sesenta por ciento, obtendríamos un total de entre 500 y 800 copias. Debemos tener también en cuenta las copias que se hiceron fuera de Roma para circular a nivel regional. En España y Portugal, por ejemplo, se hacían al menos seis copias de las cartas de los colegios ibéricos, destinadas a las propias provincias ibéricas y a la India, Brasil y África. Las Constituciones exigían asimismo que se hicieran copias aparte para cada uno de los colegios a nivel provincial, pero es poco probable que esto se observara rigurosamente. En cualquier caso, el número de cartas producidas cada año por la Compañía en su conjunto fue extremadamente elevado. La red funcionaba lo suficientemente bien como para que Polanco, ante las crecientes presiones sobre la curia de Roma a fines de la década de 1550, pensara en un nuevo gran ajuste.

66 Sobre las colecciones portuguesas, véase Epistolae S. Francisci Xaverii, ed. G. Schurhammer, 2 vols., Roma, IHSI, 1944-1945, vol. 1, pp. 187*-197*; debatido en MB, passim.

67 Constitutiones (nota 13) vol. 2, pp. 620-622.

68 Véase $L Q$, t. 4 (1556), y t. 5 (1557-1558). 
Como hemos podido observar hasta ahora, la producción y circulación de quadrimestres era el resultado de un equilibrio entre la recopilación de información, la composición y las actividades de copia dentro de la red jesuita. Roma jugó un papel importante a la hora de coordinar el intercambio de cartas y, directa e indirectamente, las modeló en su forma y contenido. Si en 1550 Polanco estaba satisfecho por haber convertido a Roma en el centro principal de copia y reenvío de noticias, la expansión de la orden hizo que, a finales de la década, la labor de copia fuese demasiado pesada para la curia romana de la Compañía.

Como consecuencia, en 1560, Polanco trató de sacar a Roma de la ecuación casi por completo $^{69}$. Las cartas ya no pasarían por el centro romano para ser editadas, traducidas y copiadas, sino que los rectores de los colegios y los superiores provinciales asumirían directamente esa responsabilidad. Obviamente, el cambio de sistema liberaba a la curia general de una pesada carga. "Hasta aquí -escribía Polanco-se ha procurado en Roma de aliviar a todos las Provincias del travajo de screvir todas las letras Quadrimestres que eran necessarias para los collegios y casas de la Compañía, haziendo las copias para unas partes y otras como se apunta en las Constitutiones", pero, a partir de entonces, las copias se harían a nivel local. Esto aumentaba las obligaciones de rectores y superiores provinciales, que debían encontrar copistas cualificados y controlar la distribución. Los superiores provinciales debían garantizar que se hiciese una copia de cada carta para cada provincia de la Compañía. Para las provincias en las que se hablaba el mismo idioma se enviarían copias en vernáculo y para el resto de provincias, debía hacerse en latín. Polanco justificaba así este cambio: "Y si esto parece difficil de esecutar en cada parte, mire V.R. lo que sería si en Roma se huviessen de hazer todas estas copias, porque de cada collegio desos son menester treze, más haziendose cada 4. meses estas copias"70. Para la circulación local de las cartas se introdujo también un nuevo mecanismo, que Polanco había experimentado personalmente en Roma al mandar noticias a los colegios $\operatorname{cercanos}^{71}$. En vez de hacer una copia para cada colegio de la provincia, como estipulaban las Constituciones, las cartas debían circular de una casa a otra, sin pasar más de una semana en ninguna de ellas, remitiéndose después de nuevo al provincial, que era el responsable de conservarlas ${ }^{72}$.

El trabajo que antes se hacía en Roma se ejecutaba ahora a nivel regional y esto significaba mucho más que hacer copias. El esfuerzo de reproducir las prácticas romanas en el conjunto de la orden se tradujo en toda una serie de instrucciones detalladas acerca del lenguaje, el estilo y el contenido: la Ratio scribendi de $1560^{73}$. Los rectores debían cuidar de que las cartas estuviesen escritas correctamente (emendatissimas), y a los

69 "Qua ratione scribendi uti debeant qui extra Urbem in Societatem nostra versantur", ARSI, Instit. 117, fols. 179r-182r. Comentada a grandes rasgos en Scaduto, M.: Storia della Compagnia di Gesù in Italia, vol. 3: L'epoca di Giacommo Lainez: il governo (1556-1565), Roma, La Civiltà Cattolica, 1964, pp. 217226; Delfosse, A.: "La correspondance jésuite: communication, union et mémoire: les enjeux de la Formula scribendi", Revue d'histoire ecclésiastique", 104 (2009), pp. 71-114.

70 ARSI, Hisp. 66, fol. 67r.

71 Carta de Polanco a Everardo Mercuriano, en Perugia (17-9-1552), MI Epp., t. 4, p. 434: “y que las torne a embiar a Roma, vistas". Véase también ARSI, Ital. 62, fol. 181v.

72 Polanco, "Ratio scribendi", op. cit., (nota 45), fol. 179v; MI Epp., t. 4, p. 434.

73 Polanco, "Ratio scribendi", op. cit., (nota 45). Se enviaron también resúmenes en vernáculo de la "Ratio", referentes en su mayoría a cuestiones prácticas sobre la copia y la circulación. Véase la carta de 
superiores provinciales se les ordenó que las sometieran a un escrutinio y corrección adicionales ${ }^{74}$. "Y por amor de Dios - rogaba Polanco- que se tenga cuidado que sean muy bien revistas las cosas que se scriven, porque no se ha de pensar que se emendaran acá como hasta aquí, las que se enbian de cada parte [...] y despues de bien revisto el original se saquen allá y se colacionen las copias"75. Las cuestiones de lenguaje, estilo y contenido debían ahora supervisarlas directamente los superiores provinciales, pues en Roma, advertía Polanco al provincial portugués, "se enbían como vienen""

Las condiciones de publicación y circulación manuscrita hicieron que la idea de carta "original" perdiese casi todo su significado. A este respecto, la colección de Alcalá arroja luz sobre el entorno material en que circularon estas misivas. Aunque a veces los superiores de las misiones ultramarinas firmaban varias copias de una misma carta, éstas circulaban de modo autónomo. Por eso, en la colección de Alcalá, hay dos ejemplares de una misma carta, posiblemente transcritas en Portugal a partir de dos copias que circulaban de modo independiente. Los copistas portugueses introducían a veces indicaciones como "Recebida a dos de Agosto de 1562", fecha en que la carta había llegado a Portugal. Puesto que las misivas se enviaban normalmente en remesas desde la India y el Brasil, también se solían redistribuir en remesas desde Portugal. Por ello, en ocasiones, encontramos grupos de cartas copiadas por una misma mano, mientras que, otras veces, se trata de cartas transcritas sistemáticamente por diferentes copistas, como es el caso de una remesa de misivas del Japón, enviadas a Alcalá en $1561^{77}$. Aunque lo más usual es que se indicase claramente que se trataba de copias ("Copias de algunas cartas" o "Copia de una de Goa"), era común incluir elementos gráficos en relación con su envío desde los territorios de ultramar. Dos copias distintas de una carta de Goa de 1561, por ejemplo, una que circuló por Castilla y otra que lo hizo en Aragón, incluyen ambas la "vía" o ruta de envío de la carta desde la India: "Del collegio de Goa. de la conversion de los infieles deste ano de 1561. 3.a via de la india"78. Algunas de las cartas de Alcalá también incluyen indicaciones de su viaje itinerante de colegio en colegio, tales como "Vista en Toledo" o "Leída en Ocaña". El itinerario de la carta anual de Nueva España de 1579 fue trazado por adelantado en Madrid, circulando posteriormente por 17 colegios $^{79}$. Por su parte, las cartas que circularon por Aragón contienen indicaciones semejantes: "Vista en Gandía", "Vista en Valencia"80. Hasta el año 1565, Alcalá recibió cartas desde más de treinta lugares diferentes de Europa y, por entonces, cerca de 65 casas jesuitas escribían quadrimestres con mayor o menor regularidad. A medida que la

Polanco a Antonio Araoz (25-3-1560), ARSI, Hisp. 66, fol. 67r; Carta de Polanco a D. Lanoy, en Ingolstadt (1-2-1561), ARSI, Germ. 104, fol. 297r.

74 Polanco, "Ratio scribendi", op. cit. (nota 45), fol. 179v.

75 ARSI, Hisp. 66, fol. 67r.

76 Polanco, J.: "Para Provinçial de Portugal" (12-3-1562), ARSI, Instit. 206, fol. 83v.

77 "Copias de algunas cartas que venieron de la India en el año de 1561 que se an de embiar a la provincia de Castilla", en Varia historia rerum a Societate Iesu gestarum extra Europam, APHT, Ms. C-210/3, fols. 145r-152v. Las cartas están fechadas entre 1557 y 1560.

78 APHT, Ms. C-210/3, fol. 177v (para Castilla); AHN, Jes. leg. 270/83 (para Aragón). Cfr. DI, t. 5, p. 271.

79 APHT, Ms. C-210/3, fol. 565v: "Esta annua vaia de Madrid [a] alcala, de Alcala a Huerte, de Huerte a Cuenca, de Cuenca al Villarejo, del Villarejo a Belmonte, de Belmonte a Murcia, de Murcia a Caravaca, de Caravaca a Segura, de Segura a Toledo, de Toledo a Oropesa de Oropesa a plasençia, de Plasençia a Navalcar.o de Navalcar.o a Ocaña. de alli vuelva al P.e Provincial".

${ }^{80}$ AHN, Jes. leg. 270/63, fol. 6v. 
orden fue expandiendo sus misiones fuera de Europa durante la segunda mitad del siglo XVI, Alcalá acabaría por recibir -junto con el goteo constante de misivas procedentes de la India y Brasil- copias manuscritas de cartas del Congo, Angola, Etiopía, Florida, Cuba, México, Perú, Paraguay, China, Japón y Filipinas.

$* * *$

Los cambios introducidos en 1560 significaron que en Roma se necesitase copiar menos, pero esto no redujo el número de cartas que circularon dentro de la Compañía en su conjunto. En 1564, resultaba necesario hacer copias de quadrimestres para las 16 provincias europeas (incluyendo Roma) y se producían entre cuatro y seis copias adicionales para distribuirlas en Brasil y la India. A esto se sumarían las misiones jesuitas de Angola y el Congo y las misiones de la América española, que comenzarían pronto a funcionar.

A fines de 1564, se introdujeron en el sistema algunos cambios. El primero de ellos afectó a la frecuencia, pues las quadrimestes quedaron extinguidas. En lugar de escribir cada cuatro meses, los rectores de los colegios y otros superiores locales deberían enviar noticias dos veces al año. Este cambio estuvo probablemente basado en la propia práctica de Polanco. Durante la década de 1550, él o sus asistentes enviaban habitualmente desde Roma una carta cada cuatro meses, pero, a partir de 1560, sólo se enviaron dos veces al año ${ }^{81}$. El segundo supuso reducir la intensidad del intercambio de noticias. En adelante las noticias de cada colegio ya no circularon por separado, sino que se recopilaban bajo la supervisión del provincial en una única carta informativa, en la que se atribuía una sección o capítulo propio a cada uno de los colegios y casas de la provincia. El tercero de los cambios trató de reducir el número de copias que se hacían. Las provincias españolas y Portugal pasaron a compartir una única copia y, de modo similar, se emparejaron otros territorios. Esto supuso que cada provincia tuviese que producir sólo ocho copias ${ }^{82}$.

En 1565, tuvieron lugar nuevos cambios como resultado de las discusiones de la segunda congregación general de la Compañía, convocada para elegir a Francisco de Borja como nuevo general. La frecuencia se redujo aún más, a una vez al año, adaptándose posiblemente al ritmo de intercambio con las misiones de ultramar. Polanco ya había sugerido algo así, indicando que, puesto que las cartas sólo se despachaban una vez al año a la India y a Brasil, los colegios podían quizá mandar una carta anual a Portugal en lugar de tres quadrimestres ${ }^{83}$. A pesar de que se redujo drásticamente la frecuencia, se descartó el plan de 1564 para recopilar cartas provinciales. Cada colegio seguiría recopilando y haciendo circular su propia annua -el nombre dado ahora

81 Este cambio no estaba señalado en la "Ratio scribendi" de 1560, pero resulta evidente en las cartas que se han conservado. Algunas de ellas están reunidas en ARSI, Rom. 126a y Rom. 127. Véase también Polanci Complementa, 2 vols., Madrid, Typ. G. López del Horno, 1916-17, vol. 1, pp. 218, 248, 282.

82 Carta de Polanco a los superiores provinciales (ca. 30-11-1564), ARSI, Ital. 65, fols. 247v-248r; véase también (con fecha de diciembre) en Beati Petri Canisii Societatis Jesu, Epistolae et Acta, ed. O. Braunsberger, 8 vols., Freiburg, Herder, 1896-1923, vol. 4, pp. 750-752.

83 Polanco, "Capitulos de una del Padre Polanco por comission del Padre General a la Provincia de Portugal” (1563), ARSI, Instit. 208, fols. 376v-377r. 
a las cartas-, pero, en lugar de las ocho copias exigidas en 1564, el número se elevó a diez. En Europa, una copia de cada carta habría de ser compartida entre dos provincias y no se enviaría un ejemplar específico a la curia de Roma sino que ésta compartiría las noticias con la provincia de Toscana. De modo similar, las provincias de Castilla y Andalucía contarían con un único ejemplar de cada carta y Toledo y Aragón con otro ${ }^{84}$.

En términos generales, se redujo notablemente la intensidad en la circulación de noticias dentro la orden. Y, en 1571, disminuyó aún más, tras la reunión de la congregación de procuradores jesuitas de ese año, que retomó el plan de 1564 para que cada provincia enviase una única carta. Tal y como explicaron los jesuitas de Andalucía, este cambio era necesario por "lo poco que ya se estiman" los trabajos que conllevaba el tener que copiar misivas y por los costes del transporte ${ }^{85}$. A fines de 1571, se había puesto en marcha la nueva organización y, en 1581, se volvieron a introducir nuevos cambios que redujeron aún más el número de copias exigido. Se ordenó a cada provincia que mandase su carta únicamente a Roma, donde se prepararía una carta general resumiendo las actividades de toda la orden. Se calculó que ahora sólo serían necesarias 42 cartas, en lugar de las 442 que se hacían anualmente: una carta enviada a Roma desde cada una de las 21 provincias y 21 copias del resumen general, enviado desde Roma a las provincias. Finalmente, la carta anual de Roma acabó por imprimirse, lo que disminuyó aún más el papel de la publicación manuscrita en la circulación de las cartas edificantes ${ }^{86}$.

Los colegios jesuitas no fueron, claro está, chancillerías seculares, pero jugaron un papel fundamental en la copia y la circulación de los documentos jesuitas. En este sentido, las cartas edificantes ocuparon una posición única en la cultura documental de la Compañía. Quadrimestres y annuas fueron pensadas para un uso y circulación inmediatos. Cuando llegaban a una casa o colegio jesuitas, habitualmente se leían en el refectorio. En ocasiones, se hicieron colecciones más permanentes de cartas para este propósito,

\footnotetext{
84 "Ratio scribendi" (1565), ARSI, Instit. 110, fols. 216-221, y en concreto fol. 217r. Aquí se contienen instrucciones más detalladas que en la "Formula scribendi", promulgada junto con los decretos de la segunda congregación general de 1565; véase Institutum Societatis Iesu, 3 vols., Florencia, Typ. a SS. Conceptione, 1893, vol. 2, pp. 205-206.

85 "De Actis in Congregatione Provinciali Societatis Jesu Provinciae Bethicae" (1571), ARSI, Congr. 41, fol. 40r-v: "Proposuse de las Annuas de los Collegios lo poco que ya se estiman por escrivirse en ellas quasi unas mismas cosas y ya escritas y por venir en ellas cosas algunas vezes no tan edificativas ni tan limadas como convendria. Ultra desto hazen mucha costa de portes. Parecio bien a todos se propusiese a nuestro Padre si le pareciese buen medio uno que aca a todos parecio. Que cada año escrivan los Rectores al Provincial las cosas de edificacion de su Collegio y el Provincial haga una Annua de toda la Provincia de las cosas de mas momento, y destas se hagan los tres lados conforme a las Nacciones señaladas en el orden dado. En sentido parecido, véase "Provinciae Siciliae Annuae" (diciembre de 1571), ARSI Sic. 182, fol. 216r: "Habbiamo ricevuto il nuovo ordine mandato da V.P.tà circa il modo di scrivere la lettra annuale cioè che il Provinciale di ciascuna provincia la debbia scrivere comprendendo in una sola lettra tutte le cose d'edificatione di tutti li collegii di sua Provincia". Véanse, además, las annuas provinciales de 1572 en ARSI, Germ. 141, 1r fols. (Lovaina), Med. 75, fol. 91r (Milán). El nuevo procedimiento se ratificó en la "Formula scribendi" de 1573 , DI, t. 9, pp. 720-721.

86 Institutum Societatis Iesu, op. cit. (nota 84), vol. 2, p. 256. Para la fortuna posterior de las annuas a lo largo de los siglos XVI y XVII véase FrIEDRICH, op. cit, (nota 11), pp. 20 y ss.
} 
como es el caso de los volúmenes elaborados para las casas portuguesas de la Compañía. Por tanto, las cartas no fueron únicamente leídas como noticias, sino que fueron incorporadas a la cultura textual -más amplia- de la orden. Algunas cartas escogidas, en particular las de las misiones de ultramar, se compartían habitualmente con patronos y otras personas que apoyaban a la Compañía. Como ha mostrado Federico Palomo, las cartas edificantes funcionaron como extensión de la misión evangélica de los jesuitas, siendo reenviadas, releídas y reincorporadas a las actividades pastorales ${ }^{87}$.

Algunos testimonios procedentes del Colegio de Montesión, en Palma de Mallorca, ofrecen un vívido ejemplo del modo en el que las cartas edificantes se reutilizaron. A pesar de que la colección de misivas del colegio no se ha conservado, algunos materiales para la predicación de finales del siglo XVI muestran cómo las cartas seguían usándose mucho tiempo después de haber dejado de ser noticia. El ejemplo más obvio es el de un índice alfabético de lugares comunes en latín, confeccionado a partir de una colección de annuas de los años 1581-1595 (probablemente las cartas impresas en latín que cada año se enviaban desde Roma). El índice, en un pequeño cuaderno en octavo de 23 folios, está todo él escrito en letra clara y parece evidente que fue compilado a partir de apuntes o notas en papel. Cuenta con 74 epígrafes, tales como blasfemia, conversión, demonios, herejes, paciencia, reliquias, etc. Dentro de cada entrada, encontramos anotaciones que van de unas pocas palabras a un resumen de una sola línea, seguidas de una indicación del año, la localidad o la provincia en que ocurrió el episodio y un número de página que remite a la colección de cartas del colegio. El índice hace referencia a cartas de 22 provincias europeas y a las misiones de Asia y del Brasil. En él encontramos, por ejemplo, una entrada relativa a la conversión de un campesino en Austria, en 1588, y otra relativa a un demonio espléndidamente adornado que se apareció en Perú, en $1591^{88}$. Otro cuaderno de exempla utilizado para la predicación revela asimismo algo del contexto en el que las cartas se leían y usaban. A pesar de no seguir aparentemente ningún orden, los materiales del cuaderno están colocados por lugares comunes y los pasajes copiados de las annuas complementan a otros procedentes de los padres de la Iglesia, vidas de santos y otros textos eclesiásticos y devocionales. Al estar escrito en castellano, el cuaderno hacia fácilmente accesibles los extractos provenientes de textos latinos, permitiendo que los miembros del colegio pudiesen incorporar directamente estos pasajes a sus sermones ${ }^{89}$.

Un tercer cuaderno del colegio de Mallorca contiene, por último, más de 700 páginas de citas, extraídas exclusivamente de las annuas. Resulta interesante el hecho de que el preámbulo desaconsejase a los predicadores que hiciesen referencia explícita a las propias annuas, pues la mayoría de los oyentes habrían de quedar desconcertados. Era mejor, aconsejaba el cuaderno, "dezir en una carta que escrivió un padre de tal provincia,

87 Palomo, op. cit. (nota 5, 2005); Palomo, F.: "De algunas cosas que sucedieron estando en misión. Espiritualidad jesuita y escritura misionera en la península Ibérica (siglos XVI-XVII)”, en A Companhia de Jesus na Península Ibérica nos séculos XVI e XVII: espiritualidade e cultura, 2 vols., Oporto, CIUHE/ Universidade do Porto, 2004, vol. 1, pp. 119-150, concretamente pp. 131-133.

88 "Index exemplorum, quae ab anno 1581 usque ad 1595 in annuis litteris continentur, per alphabetum digestus", BRAH, Ms. 9/3171, fols. 151r-174r.

89 BRAH, Ms. 9/2426. 
o de tal collegio, año tal, se cuenta esto, o aquello" ${ }^{90}$. Al igual que el anterior cuaderno, éste también estaba escrito en vernáculo, habiendo sido claramente recopilado para su uso colectivo. El encargado de confeccionarlo explicaba que el recurso a los ejemplos en la predicación tenía varias funciones, entre las cuales el ornato, la amplificación y la verificación. Añadía que los ejemplos debían ser verdaderos, serios e "illustres" y, aunque admitía que los exempla antiqua tenían más autoridad, indicaba que "los modernos tienen tambien mucha fuerça principalmente si son domésticos y de los nuestros de nuestra nación y casa y familia y religion" ${ }^{91}$.

Los jesuitas leían y escuchaban cartas edificantes de modo regular, y al participar en su producción, circulación y uso tenían si cabe una mayor conciencia de los vínculos que unían al más remoto de los colegios con la extensa red jesuita. Una carta, por ejemplo, como la que escribió en Valencia, en 1560, Jerónimo Ros, parece escrita por un avezado veterano, a pesar de que Ros era en realidad un escolar jesuita de 21 años:

Siempre me contento muchissimo la loable costumbre de nuestra compañía que cada quatro meses se le dé cuenta y aviso a V.P. de lo que hazen los nuestros en las partes donde se hallan. Porque de más de tener entendido ser cosa conveniente y necessaria haver este trato y communicatión entre los miembros y la cabeça. Toda vía paresce no ser este sólo el fructo de este exercitio, porque para mover los coraçones y encenderlos y animarlos para empresas arduas y difficultosas, que mejor medio puede haver que ponerle á uno delante los ojos lo que hazen y emprenden sus hermanos? En esta procuraré de apunctar con brevedad, algunas de las cosas que su Magestad se digna obrar por los instrumentos que tiene en este collegio ${ }^{92}$.

Esta carta recapitula de forma sucinta y amplifica la ideología que subyacía en la comunicación jesuita, siendo expresiva del modo en el que el intercambio de textos escritos acabó por interiorizarse dentro de la orden como una práctica social de singular valor. Las cartas edificantes proporcionaron un punto de contacto crucial entre la construcción colectiva de la identidad jesuita y la interiorización de las técnicas de escritura. No fue una casualidad que el colegio jesuita fuese al mismo tiempo el lugar de producción y el objeto de la descripción de las quadrimestres y, más adelante, de las annuas. El profundo compromiso espiritual y psicológico con las cartas edificantes supuso un fuerte estímulo para la reproducción de prácticas escritas estandarizadas. La elaboración y circulación de estos textos supuso reproducir a nivel gráfico y material las prácticas sociales disciplinadas de intercambio de las que dependían, en general, los flujos de información en el seno de la orden.

Traducción del inglés: Saúl MarTínEz BERMEJO

Revisión de la traducción: Federico PALOMO

\footnotetext{
90 "Modo de contar los exemplos", BRAH, Ms. 9/2420, fol. 3r.

91 Ibidem, fol. 1r.

92 Carta de J. Ros, en Valencia, a Laínez (2-1-1560), ARSI, Hisp. 97, fols. 6r-v. Sobre Ros, véase $L Q$, t. 6 , p. 465 , n. 1 .
} 